\title{
The red meat allergy syndrome
}

\section{in Sweden}

Danijela Apostolovic ${ }^{1,2}$, Thi Anh Thu Tran ${ }^{1}$, Maria Starkhammar $^{3}$, Sara Sánchez-Vidaurre ${ }^{1}$, Carl Hamsten $^{1} 4^{*}$, MARIANNE VAN HAGE ${ }^{*}$

'Department of Medicine Solna, Immunology and Allergy Unit, Karolinska Institutet, and Karolinska University Hospital, Stockholm, Sweden, ${ }^{2}$ Center of Excellence for Molecular Food Sciences, Faculty of Chemistry, University of Belgrade, Serbia, ${ }^{3}$ Department of Internal Medicine, Södersjukhuset, Stockholm, Sweden, ${ }^{4}$ Center for Inflammatory Diseases, Karolinska Institutet, Stockholm, Sweden

\section{Summary}

In the last decade, a novel type of food allergy presenting with severe allergic reactions several hours after consumption of red meat has been recognized. The allergic responses are due to $\mathrm{IgE}$ antibodies directed against the carbohydrate epitope galactose$\alpha-1,3$-galactose ( $\alpha$-Gal) found in mammalian meat. This review presents the red meat allergy syndrome in Sweden, discusses the features of the immune response to carbohydrates, and highlights the presence of heat stable $\alpha$-Gal-containing proteins in meat.

The number of diagnosed red meat allergy cases in Sweden has increased significantly over the past few years. All patients have been tick bitten. Our recent work has shown that $\alpha-G a l$ is present in the European tick Ixodes ricinus (I. ricinus), thus potentially explaining the strong association between anti- $\alpha-G a l$ IgE and tick bites, with development of red meat allergy as a secondary phenomenon. Further studies using immunoproteomics have identified novel $\alpha$-Gal-containing meat proteins that bound IgE from red meat allergic patients. Four of these proteins were stable to thermal processing pointing to the fact that the allergenicity of red meat proteins is preserved in cooked meat. In keeping with the fact that the $\alpha-\mathrm{Gal}$ epitope is structurally related to the blood group B antigen, a positive association with the B-negative

\section{Introduction}

Allergy to mammalian meat is rare even though meat is a main source of protein in Western societies. Initially, the identification of meat-derived allergens focused on protein antigens recognized by patients who reported allergic reactions occurring rapidly after exposure $[1,2]$. However, during the

*shared last authorship blood groups among our red meat allergic patients was noted. A selective IgE reactivity to the pure carbohydrate moiety was observed when investigating the specificity of the $\alpha-\mathrm{Gal}$ immune response. $\operatorname{IgE}$ from red meat allergic patients does not recognize the other major mammalian carbohydrate, N-glycolylneuraminic acid (Neu5Gc), also present in high amounts in red meat. Furthermore, neither common cross-reactive carbohydrate determinants (CCDs) from plants nor venoms are targets of the IgE response in these patients.

Taken together, the $\alpha$-Gal carbohydrate has shown to be a potentially clinically relevant allergen that should be taken into account in the diagnosis of food allergy. Many new findings in the field of red meat allergy have been obtained during the past years, but further efforts to understand the process of digestion, absorption, and delivery of $\alpha$-Gal-containing molecules to the circulation are needed.

Cite this as Apostolovic D, Tran TAT, Starkhammar M, Sánchez-Vidaurre S, Hamsten C, van Hage M. The red meat allergy syndrome in Sweden. Allergo J Int 2016;25:49-54

DOI: 10.1007/s40629-016-0098-0

\section{Key words}

a-Gal - carbohydrate - meat tick bites Sweden - beef processing
Submitted

July 13,2015

\section{Accepted}

August 15, 2015 
last decade a novel type of meat allergy has been reported where patients have severe allergic reactions occurring several hours after red meat intake [3]. This unique presentation represents a challenge in linking ingestion to reactions for both patients and clinicians.

The allergic reactions were shown to be caused by IgE antibodies directed against a carbohydrate epitope, $\alpha$-Gal $[4,5,6]$, which is abundantly expressed on glycolipids and glycoproteins from non-primate mammals and some lower primates. In humans and higher primates, the gene encoding alpha-1,3-galactosyltransferase is not functional and no $a-\mathrm{Gal}$ is synthesized [7]. Although IgG antibodies to $\alpha-\mathrm{Gal}$ are widely expressed in humans [8], presumably in response to continuous exposure to the $\alpha$-Gal epitope via gut microorganisms [9], IgE antibodies to $\alpha-G a l$ are not. An IgE antibody response to $\alpha-G a l$ was first recognized when patients treated with the monoclonal antibody cetuximab experienced anaphylactic reactions upon the first injection [10]. Investigations revealed that the reactions were related to pre-existing IgE antibodies directed to the $\alpha$-Gal epitope on the Fab portion of cetuximab.

\section{Red meat allergic patients in Sweden}

When the new syndrome of red meat allergy was reported in 2009 [4, 11], three cases with severe allergic reactions several hours after intake of red meat (beef, lamb, pork, or moose) were identified at the Allergy Clinic at Södersjukhuset in Stockholm. These cases all had IgE antibodies to $\alpha-\mathrm{Gal}$. Six years later, more than 200 cases have been diagnosed in Sweden. It soon became clear that the novel food allergy syndrome was not only present in USA, Australia and Sweden, but also in several other European countries [11, 12, 13, 14, 15, 16].

In the first Swedish report 39 adult patients with allergy to red meat were described [15]. All patients reported delayed allergic reactions to red meat and IgE antibodies to $\alpha-G a l$. Nearly all patients displayed urticaria after red meat consumption and almost half of them reported anaphylactic reactions. When investigating their sensitization profile, all patients had IgE antibodies to beef and pork and many also to moose and other $\alpha$-Gal-containing allergen sources such as cow's milk, dog, and cat.

\section{Association with tick bites}

Upon questioning the patients we noted that all had been tick bitten, which is in line with previous reports showing an association between tick bites from Ixodes holocyclus in Australia [17] and Amblyomma americanum in the US [18] and red meat allergy. In Europe, a history of tick bites had been reported in four of five patients from Northern Spain with IgE antibodies to $\alpha-G a l[12]$.

We investigated whether our patients were sensitized to $I$. ricinus, the tick species found in Sweden and Europe. We noted that all except two patients had IgE antibodies to I. ricinus and that the IgE levels correlated significantly with the $\alpha$-Gal levels [15]. The finding was in line with our previous study where we provided the first direct evidence that a-Gal is present in the gastrointestinal tract of $I$. ricinus, thus potentially explaining the relationship between tick exposure and sensitization to $\alpha-\mathrm{Gal}$, leading to the development of red meat allergy [19]. The route of sensitization through the skin via tick bites seems to be of major importance for the induction of IgE antibodies against $\alpha-\mathrm{Gal}$ since these antibodies are not found in serum of subjects living in the northern arctic part of Sweden where ticks are not present [18].

As Lyme disease is generally transmitted through tick bites, we analyzed 207 patients with Lyme disease for IgE to $\alpha-\mathrm{Gal}$ and found that around one in five patients had IgE reactivity to $\alpha-G a l$. However, their antibody levels were lower compared to the red meat allergic patients. We also investigated the frequency of sensitization to $\alpha-\mathrm{Gal}$ in the general population and noted that $10 \%$ of 143 healthy blood donors from the Stockholm area, where ticks are prevalent, had IgE to $\alpha-G a l$. These results are in accordance with a report from Denmark and Spain [20]. The authors from that study concluded that the presence of $\alpha$-Gal-specific IgE is associated with a history of tick bites, atopy, and cat ownership. The latter observation probably reflects sensitization to the cat allergen cat IgA (Fel d 5w) which we have previously shown to carry $\alpha-G a l[21]$. Not only ticks but also parasites can give rise to $\alpha$-Gal sensitization. This became clear when we investigated parasite-infected non-cat allergic patients from Africa who were sensitized to cat IgA [22].

\section{Association with the B-negative blood groups}

The $\alpha$-Gal epitope is structurally closely related to the blood group B antigen [9]. Only the lack of a fucose residue on the glycan core distinguishes the structure of blood group B antigen from $\alpha-G a l$ [23]. Subjects with blood groups $\mathrm{B}$ and $\mathrm{AB}$ have been shown to produce natural anti- $\alpha-G a l$ antibodies that bind to $\alpha-G a l$ epitopes only; whereas subjects with blood groups A or $\mathrm{O}$ have antibodies that react to either $\alpha-\mathrm{Gal}$ or $\mathrm{B}$ antigen $[24,25]$. Natural antibodies against $\alpha-G a l$ moieties on non-primate mammalian tissues are often involved in acute organ rejection in xenotransplantation. With respect to the impact of the B-negative blood groups in the red meat allergy syndrome, we noticed for the first time that only two of our 39 
red meat allergic patients (5\%) belonged to the B-positive blood group which is significantly less compared with the expected number in the Swedish population (18\%) [15]. The finding is in accordance with a recent report on the relationship between IgG and IgE responses to $a-G a l$ and blood group B where IgE production to $\alpha-G a l$ was accompanied by low amounts of IgE to blood group B [26].

\section{a-Gal-containing proteins in red meat}

When the red meat allergy syndrome was recognized, efforts on identifying red meat proteins carrying the $\alpha$-Gal moiety were initiated. Two high molecular weight $\alpha$-Gal containing allergens, laminin $\gamma-1$ and the collagen $\alpha-1$ (VI) chain $(240 \mathrm{kDa}$ and $140 \mathrm{kDa}$ respectively) from Bos taurus were initially identified [27]. These findings were consistent with previous reports demonstrating cross-reactivity of red meat with gelatin, a derivative of collagen [28]. It is well known that heating or other treatments of proteins can modify IgE-binding properties by changing the conformation of epitopes. With respect to peanuts, frying and boiling has been shown to reduce the IgE-binding to the major peanut allergens, whereas roasting, which uses higher temperatures, increased the allergenicity [29].

We characterized the proteomic profile of different beef preparations (raw, medium rare, fried, and boiled) and investigated their potential allergenicity among Swedish red meat allergic patients. We noted that most of the red meat allergic patients recognized similar IgE-binding proteins of beef in a wide range of molecular weight $(25-250 \mathrm{kDa})$ [30]. The $\mathrm{IgE}$ reactivity was stronger to raw and medium rare meat compared to fried and boiled meat. Using an immunoproteomic approach, we identified 18 proteins from Bos taurus, seven of them contained a-Gal (Fig. 1). When examining different processed beef preparations, four IgE-binding $\alpha$-Gal-containing proteins were shown to be stable to heat treatment (creatine kinase M-type, aspartate aminotransferase, $\beta$-enolase, and $\alpha$-enolase) [30]. These are cytoplasmic proteins, playing essential roles in the metabolic pathways $[31,32]$. Thus, the allergenicity of red meat proteins carrying the $\alpha-\mathrm{Gal}$ epitope is preserved even upon thermal processing. These findings indicate that even thermal cooking of red meat may induce a severe delayed allergic reaction. Moreover, we noticed that red meat allergic patients also have IgE responses to non- $\alpha-G a l-c o n-$ taining beef proteins.

\section{Features of the immune response to carbohydrates}

Many food allergens are glycoproteins that contain one or several carbohydrates linked to the protein structure. Not only proteins but also carbohydrates can stimulate the production of $\operatorname{IgE}$ antibodies and be strong inducers of Th2 responses [33]. The current estimate is that $15-30 \%$ of allergic patients generate specific anti-carbohydrate IgE antibodies [34], but this IgE response has very little clinical relevance [35].

At present, $\alpha-\mathrm{Gal}$ is the only clinically relevant carbohydrate allergen from the mammalian kingdom. However, besides $\alpha-G a l$, a sialic acid named Neu5Gc is the only mammalian carbohydrate present in high amounts in beef, lamb, pork, and cow's milk [36]. Similar to $a-G a l$, Neu5Gc is found in most mammals including primates [37] but not in humans due to a mutation in the gene encoding the enzyme responsible for Neu5Gc synthesis. IgG antibodies against Neu5Gc reach up to $0.25 \%$ of total circulating IgG in some subjects which is similar to what is known regarding IgG antibodies to $\alpha-\mathrm{Gal}$, but the IgG levels to Neu5Gc and $\alpha-G a l$ have not been reported to correlate $[36,38]$. In addition to a-Gal, carbohydrates from the plant kingdom and venoms have been shown to induce an IgE response.

We investigated whether the $\operatorname{IgE}$ responses to a-Gal targeted the glycoprotein or the carbohydrate structure only. Deglycosylation of an $\alpha$-Gal containing protein, bovine thyroglobulin, significantly reduced the IgE response as compared to untreated thyroglobulin. In addition, the IgE levels against deglycosylated thyroglobulin were reduced more than hundredfold to below the cut-off $\left(<0.10 \mathrm{kU}_{\mathrm{A}} / \mathrm{l}\right)$ in two thirds of patients tested. The results indicate that the anti- $\alpha-G a l$ IgE response of red meat allergic patients is directed against the pure $\alpha-\mathrm{Gal}$ carbohydrate and is unrelated to the carrier protein itself. We furthermore scrutinized if red meat allergic patients also have an IgE response to Neu5Gc, carbohydrates from the plant kingdom or venoms. Our study revealed that red meat allergic patients neither had an IgE antibody response against Neu5Gc nor against CCDs from plant (nCup a 1, nArt v 1 and MUXF3) or venom (MUXF3) sources [39]. Taken together, IgE reactivity to carbohydrates from the animal and plant kingdom common in other allergic diseases is not of importance in the red meat allergy syndrome.

\section{Concluding remarks}

Red meat allergy syndrome is a novel type of food allergy which is increasingly recognized in Sweden. The diagnosis may be problematic as the allergic reactions are linked to red meat intake several hours before the clinical symptoms occur. The route of sensitization through the skin via tick bites seems to be of major importance for the induction of $\operatorname{IgE}$ antibodies. Characterization of the proteomic profile of different beef preparations has revealed that the $a-G a l$ epitope is commonly present in IgE-reac- 
Fig. 1: Proteomic approach for identification of a-Gal-contain-

ing proteins. Protein extracts from different processed meat (boiled and fried) were

subjected to high resolution $2 \mathrm{D}$ electrophoresis (upper panel, left side). Protein spots were examined and IgE-binding proteins were subjected to trypsin digestion (upper panel, right side) and analyzed with nLC-MS/ MS (lower panel, left side). The seven novel a-Gal-containing proteins were identified using anti-a-Gal-antibody and bioinformatics (lower panel, right side).
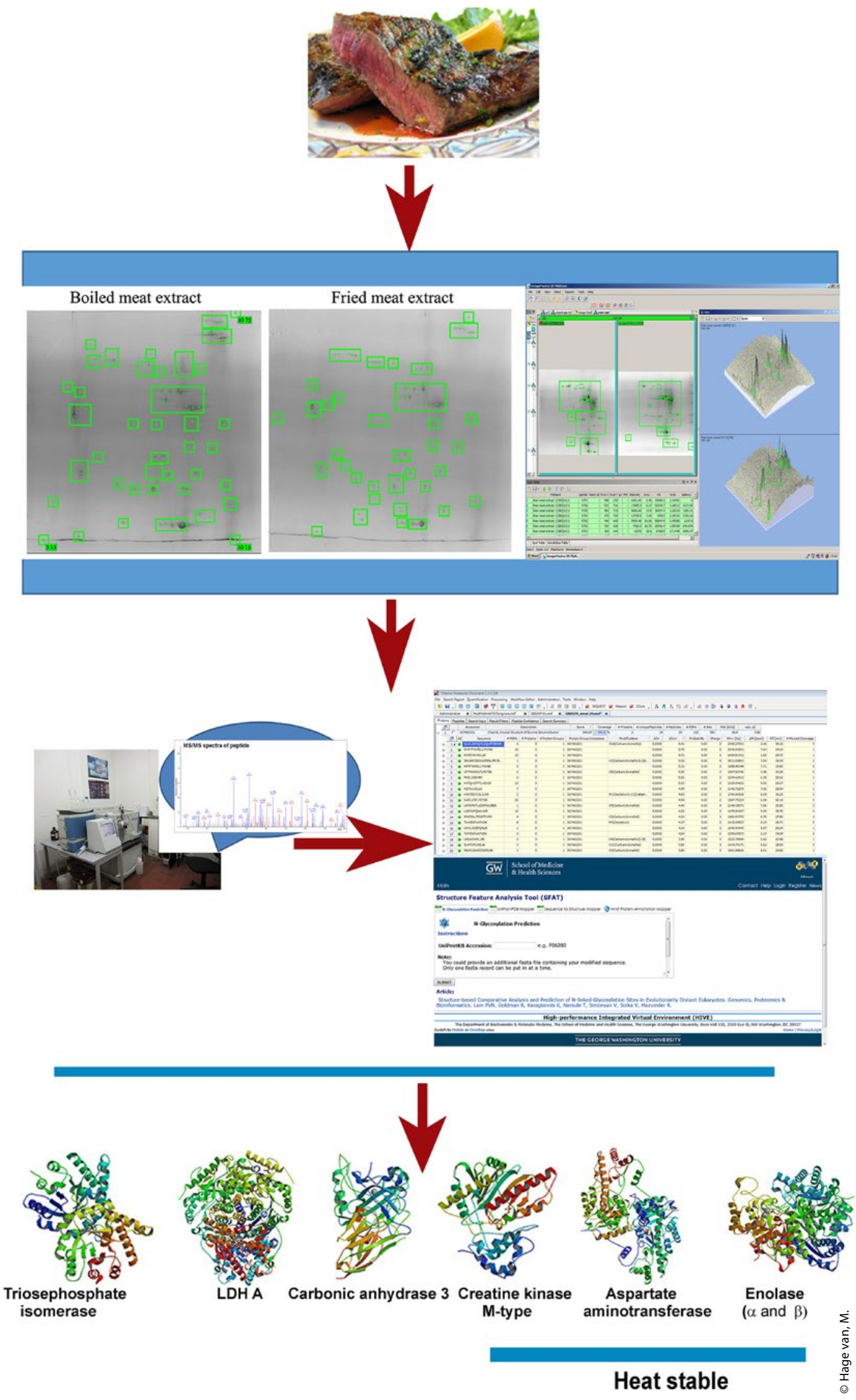
tive beef proteins, some of which are stable to heat treatment. Consequently, even cooking meat at high temperatures fails to abolish the allergenicity of several red meat proteins. Furthermore, red meat allergic patients have a selective IgE response to the pure a-Gal carbohydrate and carbohydrates from plants and venoms are not an issue in the pathogenesis and diagnosis of red meat allergy.

Taken together, the $\alpha-G a l$ carbohydrate has shown to be a potentially clinically relevant allergen that should be taken into account in the diagnosis of food allergy. Moreover, exposure to I. ricinus has increased over the last decade in Sweden and ticks are extending to the north as well as to the west of the country where they have become prevalent (Public Health Agency of Sweden, www.folkhalsomyndigheten.se). This is probably due to expanding deer and rodent populations (major tick vectors) as well as climate changes. It implies that more people in Sweden will be at risk of developing red meat allergy. The many new findings obtained over the past years have significantly increased our knowledge in the area of red meat allergy. However, further studies are needed to elucidate the process of digestion, absorption, and delivery of a-Gal-containing molecules to the circulation.

\section{Marianne van Hage, MD, PhD}

Immunology and Allergy Unit

Department of Medicine, Solna

Karolinska Institutet

Karolinska University Hospital Solna L2:04

SE-171 76 Stockholm, Sweden

E-Mail: marianne.van.hage@ki.se

\section{Conflict of interest}

The authors declare that there are no conflicts of interest.

\section{Acknowledgements}

This work was supported by grants from the Swedish Research Council, the Stockholm County Council, the Swedish Heart-Lung Foundation, the Swedish Asthma and Allergy Association's Research Foundation, the King Gustaf V 80th Birthday Foundation, the Hesselman Foundation, the Konsul Th. C. Bergh Foundation, the Magnus Bergvall Foundation, The Swedish Association for Allergology, The Center for Inflammatory Diseases, and Karolinska Institutet.

\section{Cite this as}

Apostolovic D, Tran TAT, Starkhammar M, SánchezVidaurre S, Hamsten $C$, van Hage M. The red meat allergy syndrome in Sweden. Allergo J Int 2016;25:49-54

DOI: 10.1007/s40629-016-0098-0

\section{References}

1. Werfel SJ, Cooke SK, Sampson HA. Clinical reactivity to beef in children allergic to cow's milk. J Allergy Clin Immunol 1997;99:293-300

2. Fiocchi A, Restani P, Riva E. Beef allergy in children. Nutrition 2000;16:454-7
3. Commins SP, James HR, Stevens W, Pochan SL, Land MH, King $C$, et al. Delayed clinical and ex vivo response to mammalian meat in patients with IgE to galactose-alpha-1,3-galactose. J Allergy Clin Immunol 2014;134:108-15

4. Commins SP, Satinover SM, Hosen J, Mozena J, Borish L, Lewis BD, et al. Delayed anaphylaxis, angioedema, or urticaria after consumption of red meat in patients with $\lg \mathrm{E}$ antibodies specific for galactose-alpha-1,3-galactose. J Allergy Clin Immunol 2009;123:426-33

5. Commins SP, Platts-Mills TA. Anaphylaxis syndromes related to a new mammalian cross-reactive carbohydrate determinant. J Allergy Clin Immunol 2009;124:652-7

6. Saleh H, Embry S, Nauli A, Atyia S, Krishnaswamy G. Anaphylactic reactions to oligosaccharides in red meat: a syndrome in evolution. Clin Mol Allergy 2012;10:5

7. Galili U. The alpha-gal epitope and the anti-Gal antibody in xenotransplantation and in cancer immunotherapy. Immunol Cell Biol 2005;83:674-86

8. Thall A, Galili U. Distribution of Gal alpha 1-3Gal beta 1-4GICNAc residues on secreted mammalian glycoproteins (thyroglobulin, fibrinogen, and immunoglobulin G) as measured by a sensitive solid-phase radioimmunoassay. Biochemistry 1990;29:3959-65

9. Galili U, Mandrell RE, Hamadeh RM, Shohet SB, Griffiss JM. Interaction between human natural anti-alpha-galactosyl immunoglobulin $\mathrm{G}$ and bacteria of the human flora. Infect Immun 1988;56:1730-7

10. Chung CH, Mirakhur B, Chan E, Le QT, Berlin J, Morse M, et al. Cetuximab-induced anaphylaxis and lgE specific for galactose-alpha-1,3-galactose. N Engl J Med 2008;358:1109-17

11. Jacquenet $S$, Moneret-Vautrin DA, Bihain BE. Mammalian meat-induced anaphylaxis: clinical relevance of anti-galactose-alpha-1,3-galactose IgE confirmed by means of skin tests to cetuximab. J Allergy Clin Immunol 2009;124:603-5

12. Nunez R, Carballada F, Gonzalez-Quintela A, Gomez-Rial J, Boquete M, Vidal C. Delayed mammalian meat-induced anaphylaxis due to galactose-alpha-1,3-galactose in $5 \mathrm{Eu}$ ropean patients. J Allergy Clin Immunol 2011;128:1122-4 e1

13. Morisset $M$, Richard C, Astier C, Jacquenet $S$, Croizier $A$, Beaudouin $E$, et al. Anaphylaxis to pork kidney is related to IgE antibodies specific for galactose-alpha-1,3-galactose. Allergy 2012;67:699-704

14. Fischer J, Hebsaker J, Caponetto P, Platts-Mills TA, Biedermann T. Galactose-alpha-1,3-galactose sensitization is a prerequisite for pork-kidney allergy and cofactor-related mammalian meat anaphylaxis. J Allergy Clin Immunol 2014;134:755-759 e1

15. Hamsten C, Tran TA, Starkhammar M, Brauner A, Commins SP, Platts-Mills TA, et al. Red meat allergy in Sweden: association with tick sensitization and B-negative blood groups. J Allergy Clin Immunol 2013;132:1431-4

16. Ebo DG, Faber M, Sabato V, Leysen J, Gadisseur A, Bridts $\mathrm{CH}$, et al. Sensitization to the mammalian oligosaccharide galactose-alpha-1,3-galactose (alpha-gal): experience in a Flemish case series. Acta Clin Belg 2013;68:2069

17. Van Nunen SA, O'Connor KS, Clarke LR, Boyle RX, Fernando SL. An association between tick bite reactions and red meat allergy in humans. Med J Aust 2009;190:510-1

18. Commins SP, James HR, Kelly LA, Pochan SL, Workman LJ, Perzanowski MS, et al. The relevance of tick bites to the production of IgE antibodies to the mammalian oligosaccharide galactose-alpha-1,3-galactose. J Allergy Clin Immunol 2011;127:1286-93 e6

19. Hamsten C, Starkhammar M, Tran TA, Johansson M, Bengtsson U, Ahlen $\mathrm{G}$, et al. Identification of galactose-alpha-1,3-galactose in the gastrointestinal tract of the tick Ixodes ricinus; possible relationship with red meat allergy. Allergy 2013;68:549-52 
20. Gonzalez-Quintela A, Dam Laursen AS, Vidal C, Skaaby T, Gude F, Linneberg A. IgE antibodies to alpha-gal in the general adult population: relationship with tick bites, atopy, and cat ownership. Clin Exp Allergy 2014;44:1061-8

21. Gronlund $\mathrm{H}$, Adedoyin J, Commins SP, Platts-Mills TA, van Hage M. The carbohydrate galactose-alpha-1,3-galactose is a major IgE-binding epitope on cat IgA. J Allergy Clin Immunol 2009;123:1189-91

22. Arkestal K, Sibanda E, Thors C, Troye-Blomberg M, Mduluza $T$, Valenta $R$ et al. Impaired allergy diagnostics among parasite-infected patients caused by lgE antibodies to the carbohydrate epitope galactose-alpha 1,3-galactose. J Allergy Clin Immunol 2011;127:1024-8

23. Springer GF, Horton RE. Blood group isoantibody stimulation in man by feeding blood group-active bacteria. J Clin Invest 1969;48:1280-91

24. Galili U, Buehler J, Shohet SB, Macher BA. The human natural anti-Gal lgG. III. The subtlety of immune tolerance in man as demonstrated by crossreactivity between natural anti-Gal and anti-B antibodies. J Exp Med 1987;165:693-704

25. McMorrow IM, Comrack CA, Nazarey PP, Sachs DH, DerSimonian $\mathrm{H}$. Relationship between $\mathrm{ABO}$ blood group and levels of Gal alpha,3Galactose-reactive human immunoglobulin G. Transplantation 1997;64:546-9

26. Rispens T, Derksen NI, Commins SP, Platts-Mills TA, Aalberse RC. IgE production to alpha-gal is accompanied by elevated levels of specific lgG1 antibodies and low amounts of $\lg E$ to blood group $B$. PLoS One 2013;8:e55566

27. Takahashi H, Chinuki Y, Tanaka A, Morita E. Laminin gamma-1 and collagen alpha-1 (VI) chain are galactose-alpha-1,3-galactose-bound allergens in beef. Allergy 2014;69:199-207

28. Mullins RJ, James H, Platts-Mills TA, Commins S. Relationship between red meat allergy and sensitization to gelatin and galactose-alpha-1,3-galactose. J Allergy Clin Immunol 2012;129:1334-1342 e1

29. Beyer K, Morrow E, Li XM, Bardina L, Bannon GA, Burks AW et al. Effects of cooking methods on peanut allergenicity. J Allergy Clin Immunol 2001;107:1077-81
30. Apostolovic D, Tran TA, Hamsten C, Starkhammar M, Cirkovic Velickovic T, van Hage M. Immunoproteomics of processed beef proteins reveal novel galactose-alpha-1,3-galactose-containing allergens. Allergy 2014;69:1308-15

31. Joseph P, Suman SP, Rentfrow G, Li S, Beach CM. Proteomics of muscle-specific beef color stability. J Agric Food Chem 2012;60:3196-203

32. Bax ML, Sayd T, Aubry L, Ferreira C, Viala D, Chambon C, et al. Muscle composition slightly affects in vitro digestion of aged and cooked meat: identification of associated proteomic markers. Food Chem 2013;136:1249-62

33. Bochner BS, Zimmermann N. Role of siglecs and related glycan-binding proteins in immune responses and immunoregulation. J Allergy Clin Immunol 2015:

34. Altmann F. The role of protein glycosylation in allergy. Int Arch Allergy Immunol 2007;142:99-115

35. van der Veen MJ, van Ree R, Aalberse RC, Akkerdaas J, Koppelman SJ, Jansen HM, et al. Poor biologic activity of cross-reactive IgE directed to carbohydrate determinants of glycoproteins. J Allergy Clin Immunol 1997; 100:327-34

36. Taylor RE, Gregg CJ, Padler-Karavani V, Ghaderi D, Yu H, Huang $S$, et al. Novel mechanism for the generation of human xeno-autoantibodies against the nonhuman sialic acid N-glycolylneuraminic acid. J Exp Med 2010;207:1637-46

37. Chou HH, Takematsu H, Diaz S, Iber J, Nickerson E, Wright $\mathrm{KL}$, et al. A mutation in human CMP-sialic acid hydroxylase occurred after the Homo-Pan divergence. Proc Natl Acad Sci U S A 1998;95:11751-6

38. Tangvoranuntakul P, Gagneux P, Diaz S, Bardor M, Varki N, Varki A, et al. Human uptake and incorporation of an immunogenic nonhuman dietary sialic acid. Proc Natl Acad Sci U S A 2003;100:12045-50

39. Apostolovic D, Tran TAT, Sánchez-Vidaurre $S$, Cirkovic Velickovic T, Starkhammar M, Hamsten C, et al. Red meat allergic patients have a selective lgE response to the a-Gal glycan. Allergy 2015;70:1497-500 